\title{
Free and Open Source Software Technology Adoption in the Sri Lankan Banking Industry
}

\author{
K. Aruna Chandralal Perera ${ }^{1}$ and Shahani Weerawarne ${ }^{2}$ \\ ${ }^{1}$ Ceylon Electricity Board, Colombo 1, Sri Lanka \\ ${ }^{2}$ Faculty of Engineering, Department of Management of Technology, University of Moratuwa \\ Katubadde, Sri Lanka \\ Email: ${ }^{1}$ arunape@yahoo.com, ${ }^{2}$ shahani.w@gmail.com
}

\begin{abstract}
This research explores Free and Open Source Software (FOSS) adoption in the Sri Lankan banking sector. It produces two types of results, which are unique. One is an 8-level abstract model based on the criticality for the business, which represents all the software application usage in Sri Lankan banks. Then it presents the adoption of FOSS in banks, in terms of two quantified indices, namely General FOSS Adoption Index and Category Specific FOSS Adoption Index. The first index modeled so that it represents the 'strategic nature of usage of FOSS' as well as the 'FOSS friendliness' within the bank. The second index represents the FOSS adoption in the bank, in terms of extraction of the 'best technological features out of them' and the 'level of adoption'. The results reveal that the Sri Lankan banks do not have good levels of FOSS adoption, though all the banks use FOSS applications for some purpose or another. By further drill down into the model, it was discovered that the lack of government policy initiative towards FOSS has had a causal effect on the poor adoption ratings in the Sri Lankan banking context. Further it will greatly helpful to have FOSS supportive software business in the country, which will influence banks to get better service for FOSS products.
\end{abstract}

Keywords: Open Source Software, Software Adoption, Banking Sector

\section{INTRODUCTION}

Free and Open Source Software (FOSS) has grown in leaps and bounds during the last decade, and seen wide spread adoption in domains such as, e-governance, SMEs, education, business so on. A survey of public administrations of thirteen European countries carried out six years ago reported that $78 \%$ were using FOSS [1]. Another survey in the US conducted around the same time estimated that $87 \%$ of organizations were using FOSS [2]. Another recent survey of Indian IT companies completed early this year revealed that all of them (100\%) were using FOSS in one form or the other, and that half of them considered FOSS as an option when procuring new software [3]. While most organizations using IT today, are certain to be using FOSS, the manner and the extent of FOSS usage would vary greatly across organizations.

A striking fact about FOSS in Sri Lanka is that, there are only few FOSS based software companies in the country that either develop FOSS applications or support FOSS products such as Apache, Linux, SendMail and Squid. As per the current literature available on FOSS adoption in Sri Lankan industries, many entrepreneurs seem to lack an interest in investing in FOSS, since it appears that an adequate 
demand for FOSS products does not exist. In this context, to research on FOSS adoption and to investigate the FOSS usage improvement factors would provide useful information for such people who wish to enter this market niche.

The banking sector can be considered as an area where IT has significant adoption compared to other disciplines in Sri Lanka. This is valid for state banks as well as the private banks, since they have placed usage of IT in line with their business strategies. Banks generally use IT as a differentiation strategy when offering services to their customers. Further since time value of money is a key factor related to profit[4]ability of banks, especially in the case of interest calculations and inter-banking fund transfers, the adoption of good real time IT solutions is vital to reduce overheads.

There is no known research conducted in the banking sector related to FOSS adoption. Hence, this research is a pioneer study in this domain, and can be effectively, used by governments, the banking community as well as by FOSS service providers who are interested in enhancing FOSS adoption in the banking sector, which is a rich market niche with many business opportunities. Additionally, this research presents a model which quantifies FOSS adoption among Sri Lankan banks.

Though the topic of FOSS adoption and usage has been studied by many researchers, a single measure of the 'FOSS adoption level' for industries is significant. In addition this study provides sufficient information for banks in Sri Lanka to identify strategies to improve their FOSS scores and return on IT investments.

\section{LITERITURE REVIEW}

\subsection{A Brief History of FOSS}

The origin of FOSS can be traced back to the 50s and 60s when software was sold together with hardware, and macros and utilities were freely exchanged in certain user forums. In the 80s, as software was increasingly commercialized, Richard Stallmann, then a researcher at MIT founded the Free Software Foundation (FSF) that provided the conceptual foundation for the FOSS. Stallmann began a protracted community development effort called GNU, aiming to develop a UNIX like operating system. Although this effort was not successful as intended, it led to the creation of open source infrastructure with tools and utilities, on which subsequent open source projects such as Linux could build. Today Linux operating system is a mixture of software developed in the GNU project, Linux kernel and additional components.[4]

During the last decade, FOSS phenomenon has undergone a significant transformation to be a more mainstream, commercially viable form. This accommodation with the mainstream ensures that the emergent new FOSS phenomenon will continue to thrive as a significant force in the future software landscape.

One example of big software players adopting FOSS in their business strategies is the recent acquisition of Sun (whereas Sun previously had acquired MySql) by Oracle. Nobody, not even the most die-hard open source advocates believe Oracle bought Sun with a subsidiary notion of killing off MySQL. It is a business strategy adopted within their businesses. Oracle has previously acquired open source code database companies Sleepycat and InnoDB and maintained their products as open source. Oracle has the money and is a long-term, strategic player. They went into applications to compete with SAP and have successfully done this. Now they want to out-compete Microsoft. Microsoft's database business is the fastest growing. Oracle can use MySQL to achieve a stronger developer community. This is further established with Oracle's proposal to contribute the OpenOffice.org code to the Apache Software Foundation's Incubator, and demonstrate its commitment to the developer and open source communities.

Further, mentioned below are a few recent examples related to acquisitions of Open Source companies,

- $\quad$ Xen Source for $\$ 500$ Million

- Zimbra for $\$ 350$ Million

- JBOSS for $\$ 350$ Million.

- $\quad$ ThinkCube (by Access International) - Value unknown. (A Sri Lankan example) 
By such examples it demonstrates the fact, how FOSS has influenced today's mainstream software business in a big way. Once, Microsoft CEO Steve Ballmer's famous comment that Linux is a "cancer" that threatened Microsoft. In 2010 Microsoft was trying hard not to be public enemy No. 1 to open source proponents, in some cases by making key contributions to open source code and in other cases by making Microsoft products interoperable with open source software [5].

\subsection{Foss in the business world}

Business case for adopting open source software is easy to sell. After all, the software is free and can be easily downloaded from the Internet and installed or customized as required. Organizations interested in reducing the licensing fees of proprietary software, while avoiding penalties and legal liabilities associated with their illegal use, can definitely consider FOSS a plausible alternative. However, less obvious than the cost savings but equally important are the barriers ("hidden costs") of adopting FOSS.

FOSS has created a considerable excitement in the business world during the last decade. These applications mostly developed by groups of volunteer developers have shown potential to break the current dominance of proprietary software and restrictive licenses for many business applications, reduce software development time and improve software quality, and most importantly bring much needed software applications within the reach of individuals and small businesses, which cannot afford such software.

Many organizations have caught on to FOSS and significant cost savings in technology cost savings in technology expenditure as a result. For example Amazon.com cut its technology expenditure from $\$ 71$ million to $\$ 54$ million by switching to FOSS [6].

TABLE 1: Basic Software required by a 100 user organization [7].

\begin{tabular}{|c|c|c|c|c|}
\hline $\begin{array}{c}\text { IT } \\
\text { requirement }\end{array}$ & $\begin{array}{c}\text { Proprietary } \\
\text { software }\end{array}$ & Cost US\$ & FOSS Software & $\begin{array}{c}\text { Cost } \\
\text { US\$ }\end{array}$ \\
\hline $\begin{array}{c}\text { File and Print } \\
\text { Server }\end{array}$ & $\begin{array}{c}\text { Windows 2003 } \\
\text { Server }\end{array}$ & 999.00 & $\begin{array}{c}\text { Red Hat Enterprise } \\
\text { ES Basic }\end{array}$ & 349.00 \\
\hline 100 OS clients & Windows XP Pro & $29,900.00$ & $\begin{array}{c}\text { Red Hat Linux 9.0 } \\
\text { personal }\end{array}$ & 39.95 \\
\hline $\begin{array}{c}\text { Internet access } \\
\text { and firewall }\end{array}$ & $\begin{array}{l}\text { Microsoft } \\
\text { Exchange Server 100 } \\
\text { userver 2004 ISA }\end{array}$ & $7,399.00$ & $\begin{array}{c}\text { SendMail and } \\
\text { Netscape }\end{array}$ & Free \\
\hline $\begin{array}{c}\text { Office } \\
\text { Applications }\end{array}$ & $\begin{array}{c}\text { MS Office 2003 } \\
\text { Basic }\end{array}$ & $\mathbf{3 9 , 9 0 0 . 0 0}$ & Open Office & Free \\
\hline Total US\$ & & $\mathbf{7 9 , 6 9 7 . 0 0}$ & & $\mathbf{3 8 8 . 9 7}$ \\
\hline
\end{tabular}

The Table-1 gives an idea of getting cost benefits with use of FOSS products. Though the above figures do not reveal the real situation pertaining to the usage of FOSS in view of the fact that it does not reflect hidden costs and opportunity costs involved in the usage of FOSS, it is an indication that FOSS can effectively be used to reduce the capital expenditure costs incurred and a large sum of foreign exchange, other than many other benefits, if it could be productively used. 


\section{THEORETICAL FOUNDATIONS}

\subsection{Technology adoption}

Information Systems (IS) offer the potential for substantially improving white collar performance, but performance gains are often obstructed by users' unwillingness to accept and use available systems. In an organizational context, software often controls how people work and communicate. Apart from the theoretical value, better measures for predicting and explaining IS adoption would have great practical value, both for vendors. Researchers have derived a number of models such as Technology Acceptance Model (TAM) [8] to explain what makes some IS being adopted by users than others.

\subsection{Information systems success (ISS)}

The concept of ISS is another aspect tightly related to adoption. To measure the success of these various IS, organizations are moving beyond traditional financial measures such as Return on Investment (ROI) [9] . The Enterprise System Success Model presented by Gable (2003) is one model which shows a temporal analysis of the ISS based on what it is to date and what will happen in the future.

\subsection{Evaluation of foss adoption}

The topic of FOSS usage and adoption in different classes of organizations has been studied by different researchers. We find a case study presenting the experiences of migrating public administrators to FOSS [10] . In another study, [11] findings related to literature survey related to knowledge areas such as FOSS adoption at national level, public Policy issues and adoption within public sector private sector adoption and use, developer roles in adoption and use and economic issues pertaining to open source software has been presented.

When considering opportunities and barriers to the adoption of and use of FOSS, particularly nontechnological factors, a number of themes are emergent in the literature [11].

\subsection{Quantitative analysis of foss adoption}

There have been a lot of studies related to FOSS adoption using qualitative methods, but it is very interesting to do it quantitatively. The main benefit of having a quantitative model would be that the community who use the research data will be able to grasp it clearly so that they can take very practical steps based on the same.

The research paper titled "Open Source Adoption Index": Quantifying FOSS adoption by an Organization" [3] gives a very good insight into this research area. The model described in this paper is described in detail below, since the research model presented by the author has evolved on the same. This paper presents FOSS Adoption index (FAI), which is useful for organizations and enterprises to measure the extent to which they have adopted FOSS in their functioning and operations.

According to the presented model in the paper: "Criteria (Level 1) used in defining the FAI are indicated by the subscript ' $\mathrm{i}$ ', $\mathrm{i}=1 \ldots \mathrm{N}^{(1)}$. The set of $\mathrm{N}^{(1)}$ level -1 criteria capture the most important factors or attributes that impact on the value of FOSS adoption Index in an organization belonging to the class ' 1 ', and their selection is a vital part of model building exercise. For each level ' 1 ' criteria ' $i$ ' for a class ' 1 ' organization, the level 1 criteria scores $\left(S_{i}{ }_{i}^{(1)}\right)$ are calculated using the data collected from the organizations of that class through a survey, and a weighted sum of these scores $\left(\mathrm{S}_{i}{ }^{(\mathrm{l})}\right)$ defines the FAI as explained below. Criteria (Level 2) indicated by the subscript ' $\mathrm{j}$ ', $\mathrm{j}=1 \ldots \mathrm{M}_{\mathrm{i}}$ where the finer elements to which each level-1 criteria ' $i$ ' is broken down for greater clarity and precision, in data gathering. Selection of appropriate level -2 criteria for a given level-1 criteria is vital part of model building so that impacts the on the eventual usefulness of the model. Level-2 criteria scores $\left(\mathrm{s}_{\mathrm{ij}}\right)$ are obtained from the data collected, whose weighted sum gives $\mathrm{S}_{\mathrm{i}}{ }^{(1)}$ are explained below. 
Vol. 1, No. 1 (2013) 20-34

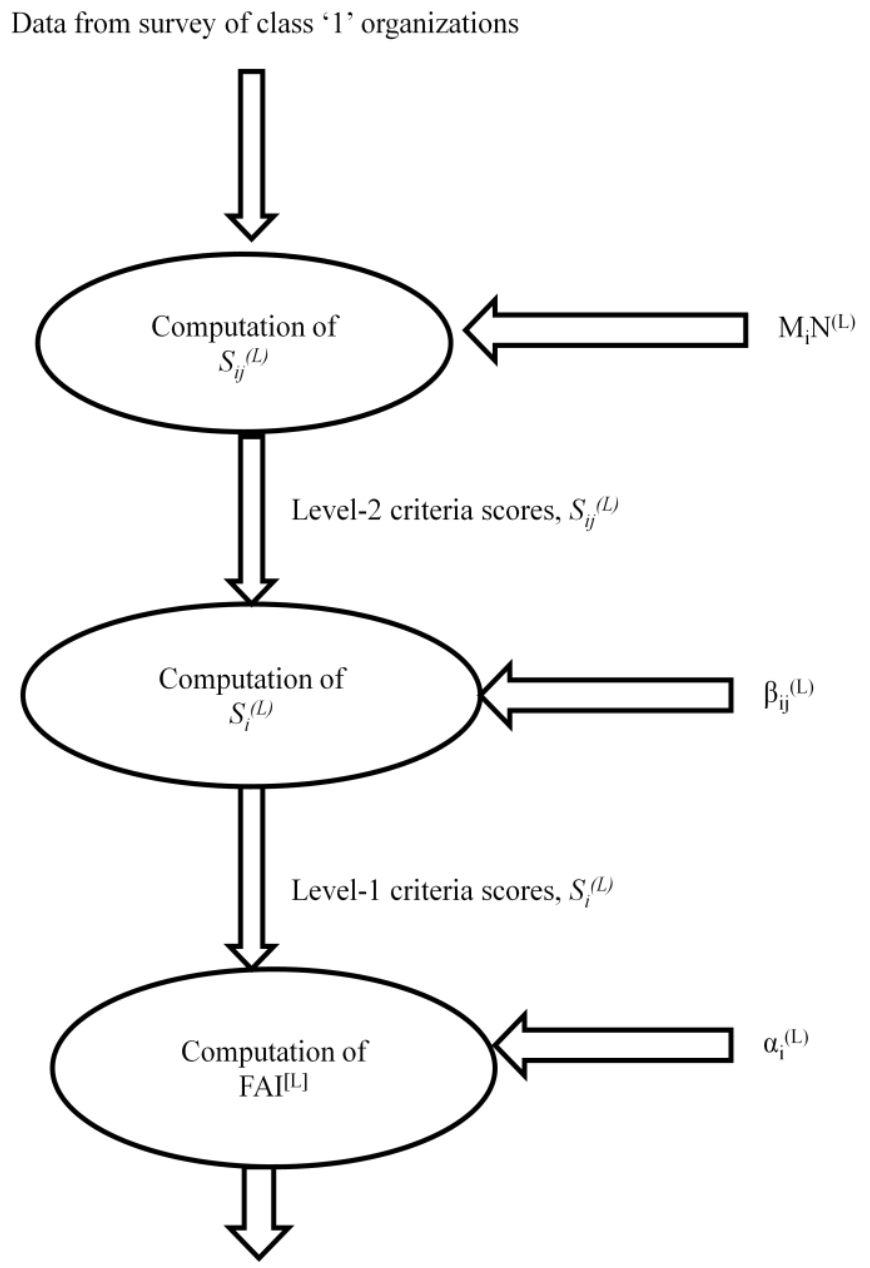

FAI ${ }^{[L]}$

FIGURE 1: Calculation of fai using 2-level model.

Model parameters $\alpha_{i j}^{(1)}, \beta_{i j}^{(1)}$ for a given class ' 1 ' are the weights defined thorough the following operations (shown for two levels) : $\mathrm{s}_{\mathrm{ij}}$

$$
F A I^{(l)}=\sum_{i=1}^{N(1)_{0}} \alpha i(l) . S i(l) ; S_{i}^{(l)}=\sum_{j=1}^{M i} \beta i j(l) \operatorname{sij}_{3}
$$

for all ' $i$ ' and ' $l$ '

$$
\sum_{i=1}^{N} \alpha i j(l)=1 \text { for all } \quad \text { ' } l \text { '; } \sum_{j=1}^{M i} \beta i j(l)=1 \text { for all ' } i \text { ' and ' } l \text { ' }
$$

With these definitions, the 2 level model is shown Figure -1 .

In addition to the absolute value of the Index, the model also yields the "sensitivity" of the FAI to a given level -1 criteria as ${ }_{i j}{ }^{(1)}$ or to a given level-2 criteria as $\alpha_{i j}{ }^{(1)} \beta_{i j}{ }^{(1}$ thereby suggesting to the management best strategies to improve its FOSS rating "[3]. 


\section{METHODOLOGY}

The research was categorized as exploratory due to the scarcity of empirical work in the research area and the interpretive approach was adopted. The case study methodology was used. A step-by-step process was used to develop the model having high reliability and validity. A pre-survey was carried out by means of unstructured interviews initially and the data was recorded in the form of short notes. Due to the highly secured and sensitive nature of this industry, considerable number of consultations and interviews were required at this stage.

The second stage of the research, which took the form of structured interviews conducted on the same basis as above steps, yielded much richer and interesting data collected from fifteen commercial and development banks operating in Sri Lanka. Twelve interviews were done in person while three were conducted over the phone.

\section{MODEL BUILDING}

This research presents the information related to FOSS adoption in following quadrants.

1. The entire software domain with respect to Sri Lankan banking sector is presented in form of abstract levels which illustrates its usage in the business perspective according to the order of the criticality of its core business, but irrespective of their technologies.

2. Quantifies FOSS adoption by mean of two types of indices namely, General FOSS Adoption Index which is a generic one and Category Specific FOSS Adoption Index, which is specific for each category.

3. The Category Specific FOSS Adoption Index is derived considering two most applicable FOSS applications, in instances where more than one FOSS application is being used within a given category.

\subsection{General foss adoption index}

General FOSS Adoption Index is a single figure between 0-10, for each bank, which is primarily a measure of the strategic nature of FOSS adoption for the business and FOSS friendliness. This research gives emphasis on the strategic nature of technology adoption, which is quite important for gaining optimum benefits out of a given technology in the long run.

A two level model was used to measure the same, having two level-1 criteria and three second level-2, criteria as described below. Total of two level criteria $(N=2)$ were identified and each of them had 3 level2 criteria $(M=3)$. The following model was developed based on the work of Sanjeew K. Saini, C. N. Krishnan and L.N. Rajaram [3]. It is used in the calculation of this index.

$$
\begin{aligned}
& \text { General FOSS Adoption Index } \quad=\sum_{i=1}^{2} \alpha i . S i_{j} S_{i}{ }^{=} \sum_{j=1}^{3} \beta i j . \text { sij }_{y} \\
& \sum_{i=1}^{2} \alpha i j=1 ; \sum_{j=1}^{3} \beta \mathrm{ij}=1 \text { for all ' } i \text { ' and ' } j \text { ' }
\end{aligned}
$$

The level-1 and level-2 criteria chosen are described below.

$i=1$ : Strategic usage of FOSS within the bank

$j=1$ : Managerial (business reasons) for using FOSS

$j=2$ : Interest about FOSS among the Senior IT Managers

$j=3$ : Awareness of FOSS among Senior IT Managers

$i=2$ : Availability of skilled FOSS trained middle managers 
$j=1 \quad$ : FOSS competence of middle managers

$j=2$ : Mode of continuous improvement of FOSS awareness

$j=3$ : Accessibility of latest FOSS related information to the community

\subsection{Category specific foss adoption index}

This index illustrates the level of FOSS adoption in the banking business environment with respect to each abstract level. This too falls between 0 and 10, and presented individually for each category. The measure related to this category is calculated using the following model.

Category Specific FOSS Adoption Index $=\sum_{k=1}^{2} \gamma k . S k$;

$$
\begin{gathered}
S_{k}=\sum_{m=1}^{3} \lambda k m . s k m, \\
\sum_{k=1}^{2} \gamma k m=1 ; \sum_{m=1}^{3} \lambda \mathrm{km}=1 \text { for all ' } k \text { ' and ' } m
\end{gathered}
$$

The choice of criteria for each level is detailed below.

$k=1: \quad$ Appropriate benefits sought from FOSS application

The facts about usage of FOSS application are studied, in respect of the real technological features during this stage. These ideas were picked specially during the literature survey, and filtered so that it applies to the banking environment, during the interviews and consultations had in the pre-survey process.

This fact is further drilled by following aspects.

$m=1 \quad$ : $\quad$ Adoption of key benefits inherited with FOSS applications

$m=2 \quad$ : $\quad$ Quality of support services

$m=3 \quad$ : Accountability of the support services

$k=2$ : $\quad$ The extent of FOSS adoption

$m=1: \quad$ Nature of usage of FOSS applications

$m=2$ : $\quad$ Proportion of usage of FOSS application

\subsection{Choice of weights at each level}

Choice of the weights of the model parameters $\alpha, \beta, \lambda$ and $\gamma$ is a very important aspect of this model. The extent of contribution of each criterion is determined by the weight associated with it. That implies, a low weight value reduces the contribution and vice- versa.

The paper on this model [3] suggests two approaches for selection of weights.

"There are two broad directions in which one can drive the choice of weights. In the so called, 'pessimistic' type of model, higher weights are assigned to those criteria whose scores are likely to be low for the chosen class. If one expects some criteria is expected to get a higher score, which is given a lower weight, effecting low range of values for the index. In the other hand, an 'optimistic' approach will assign higher weights to those criteria which are expected to attract higher scores, and vice-versa. The actual assignment of values is finally guided by heuristics 
based on the understanding that one has of the kind of scores that an 'ideal' entity in that class likely to have for its different criteria at different levels "[3]

However, in this research, much effort was put by the author to avoid these approach of 'optimistic' and 'pessimistic' nature, and trying to derive more 'realistic' values for the index by prolonged trails and experimentations during the pre-survey stage. However, 'optimistic' method was adopted in few cases as a standardization approach for quantification of indexes. Such example would be assigning lower marks for FOSS Policy as a reason for strategic adoption of FOSS, which is the Question \# 5. This would probably gain zero marks for almost all the organizations in Sri Lankan context, in absence of FOSS friendly policies by government, so giving higher marks for that would not have any extra benefit for the final figure than, all the candidates would gain 0 marks for this question.

In conclusion, the quantification process found in this research will be richer and closer to the 'reality' though further testing and experimentation of this model for the banking industry is encouraged. The weights derived for the model parameters are listed in the Table- 2

TABLE 2: Parameter values used for the general foss adoption index and the criteria specific foss adoption index.

\begin{tabular}{|c|c|c|c|}
\hline \multicolumn{4}{|c|}{$\begin{array}{l}\text { General FOSS } \\
\text { Adoption Index }\end{array}$} \\
\hline Level-1 criteria (i) & $\alpha_{i}$ & Level-2 criteria (j) & $\beta_{\mathrm{ij}}$ \\
\hline \multirow[t]{3}{*}{1} & \multirow[t]{3}{*}{0.7} & 1 & 0.4 \\
\hline & & 2 & 0.3 \\
\hline & & 3 & 0.3 \\
\hline \multirow[t]{3}{*}{2} & \multirow[t]{3}{*}{0.3} & 1 & 0.2 \\
\hline & & 2 & 0.3 \\
\hline & & 3 & 0.5 \\
\hline \multirow[t]{3}{*}{1} & \multirow[t]{3}{*}{0.7} & 1 & 0.4 \\
\hline & & 2 & 0.3 \\
\hline & & 3 & 0.3 \\
\hline \multirow[t]{3}{*}{2} & \multirow[t]{3}{*}{0.3} & 1 & 0.2 \\
\hline & & 2 & 0.3 \\
\hline & & 3 & 0.5 \\
\hline
\end{tabular}

\section{DATA ANALYSIS AND RESULTS}

\subsection{Data analysis of the stage-1 of the research (pre-survey)}

The 8-level model was one of the main findings related to the pre-survey. It is bound to following,

1. This is a logical representation of all the IT applications in a bank, irrespective to its technological aspects, but based on the business perspective.

2. It is presented on order of the criticality.

The 8-levels model is illustrated on the Table-3 
TABLE 3: The abstract category levels presented in order of its criticality.

\begin{tabular}{|c|l|l|}
\hline $\begin{array}{c}\text { Application } \\
\text { category }\end{array}$ & Application family & Example applications for the family \\
\hline 1 & Core Banking & Loan, Corporate Banking, Retail Banking, Treasury \\
\hline 2 & Infrastructure & Firewall, Web Server, Mail Servers \\
\hline 3 & Intra-banking & Cheque reconciliation \\
\hline 4 & Front office & ATM, Front Office desktop OS \\
\hline 5 & Back office & ERP, Back Office Software systems \\
\hline 6 & $\begin{array}{c}\text { Value Adding } \\
\text { Office Applications }\end{array}$ & $\begin{array}{c}\text { Word Processors, Worksheets } \\
\text { Programming } \\
\text { other applications } \\
8\end{array}$ \\
\hline
\end{tabular}

\subsection{Data analysis of the stage-2 of the research -quantification of the adoption}

The scores obtained by each bank, for General FOSS Adoption Index and the Category Specific FOSS Adoption Index are tabulated in the Table 4.

The distribution of the General FOSS Adoption Index is shown in Fig. 2. It has a mean of 1.26 while the variance is 0.30 .

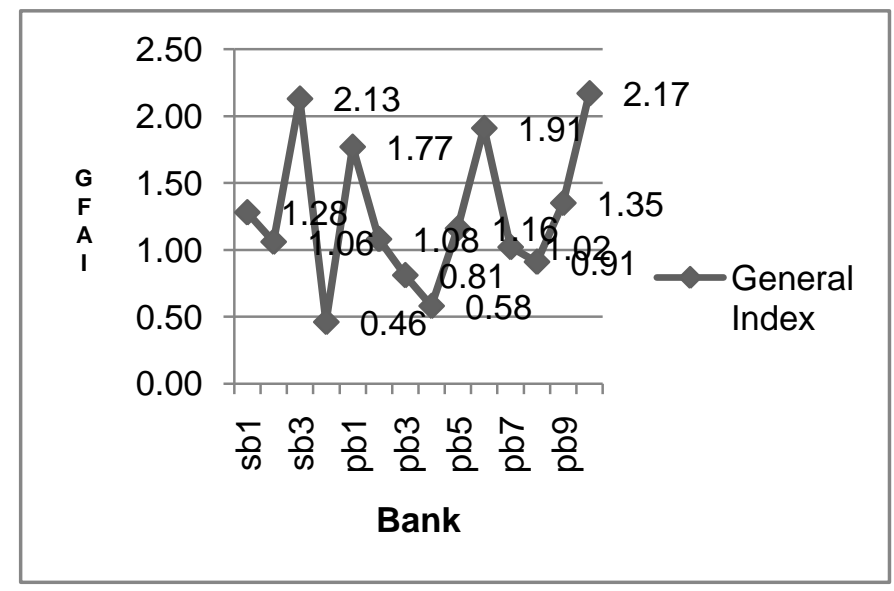

FIGURE 2: Distribution of general foss adoption index. 
Vol. 1, No. 1 (2013) 20-34

TABLE 4: The scores of general foss adoption index and category specific foss adoption index.

\begin{tabular}{|c|c|c|c|c|c|c|c|c|c|}
\hline \multirow[b]{2}{*}{ Abbr } & \multirow[b]{2}{*}{$\begin{array}{l}\text { General } \\
\text { Index }\end{array}$} & \multicolumn{8}{|c|}{ Category specific foss adoption index } \\
\hline & & c1 & c2 & c3 & c4 & c5 & c6 & c7 & c8 \\
\hline $\mathrm{sb1}$ & 1.28 & 0.00 & 1.76 & 0.00 & 0.00 & 0.20 & 0.00 & 0.00 & 1.88 \\
\hline $\mathrm{sb} 2$ & 1.06 & 0.00 & 1.10 & 0.00 & 0.00 & 0.20 & 0.00 & 0.80 & 2.50 \\
\hline $\mathrm{sb3}$ & 2.13 & 0.00 & 3.28 & 0.00 & 0.00 & 0.00 & 0.00 & 0.00 & 2.56 \\
\hline $\mathrm{sb} 4$ & 0.46 & 0.00 & 0.51 & 0.00 & 0.00 & 0.24 & 0.00 & 0.16 & 1.02 \\
\hline $\mathrm{pb} 1$ & 1.77 & 0.00 & 1.38 & 0.00 & 0.00 & 0.00 & 0.00 & 0.00 & 0.32 \\
\hline $\mathrm{pb} 2$ & 1.08 & 0.00 & 1.63 & 0.00 & 0.00 & 0.00 & 0.00 & 0.94 & 0.00 \\
\hline pb3 & 0.81 & 0.00 & 2.28 & 0.00 & 0.00 & 0.00 & 0.00 & 0.00 & 0.00 \\
\hline pb4 & 0.58 & 0.00 & 0.00 & 0.00 & 0.00 & 0.16 & 0.00 & 0.94 & 0.00 \\
\hline pb5 & 1.16 & 0.00 & 0.00 & 0.00 & 0.00 & 0.16 & 0.00 & 0.00 & 1.30 \\
\hline pb6 & 1.91 & 0.00 & 1.76 & 0.00 & 0.00 & 0.72 & 0.00 & 0.00 & 0.00 \\
\hline pb7 & 1.02 & 0.00 & 1.04 & 0.00 & 0.00 & 1.04 & 0.00 & 0.00 & 1.61 \\
\hline pb8 & 0.91 & 0.00 & 0.72 & 0.00 & 0.00 & 0.00 & 0.00 & 0.00 & 1.94 \\
\hline pb9 & 1.35 & 0.00 & 1.82 & 0.00 & 0.00 & 0.00 & 0.00 & 0.00 & 2.12 \\
\hline pb10 & 2.17 & 0.00 & 1.96 & 0.00 & 0.00 & 2.20 & 0.00 & 2.20 & 2.20 \\
\hline
\end{tabular}

The distribution of the General FOSS Adoption Index is shown in Fig. 3. It has a mean of 1.26 while the variance is 0.30 .

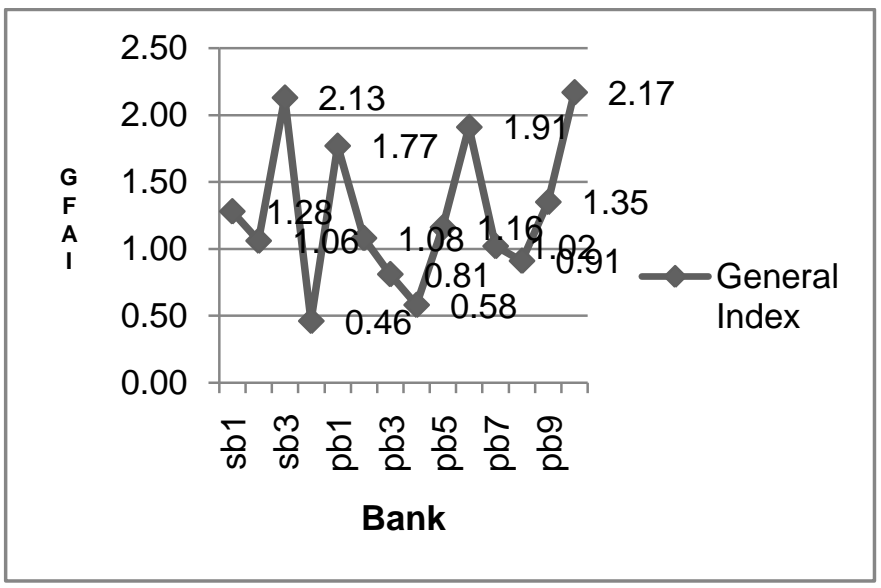

FIGURE 3: Distribution of general foss adoption index. 
Figure 3 shows that the scores are below 3 which is not a good score. In case of some banks, it is even below 0.5. As understood during the pre-survey, due to many reasons, Sri Lankan banks are not intensively exploring the opportunities with FOSS products, in the manner western banks do.

Distribution of Category Specific FOSS Adoption Index for c2 is shown on the Fig. 4.

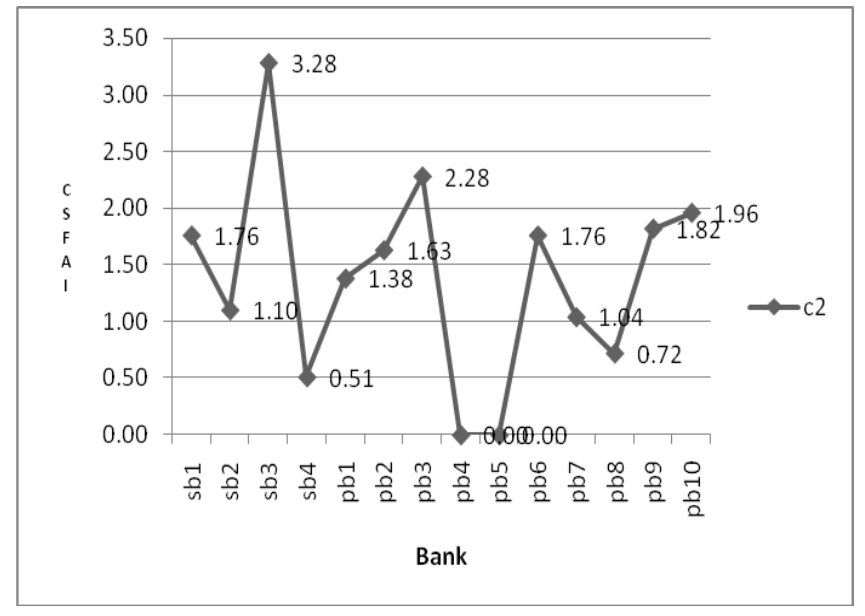

FIGURE 4: Distribution of category specific foss adoption index for c2.

It is worth to noting that, though the infrastructure category $\mathrm{c} 2$ is at a high level of criticality for a bank, there is considerable adoption in this category. The distribution of the same index for c5 is shown in Fig. 5.

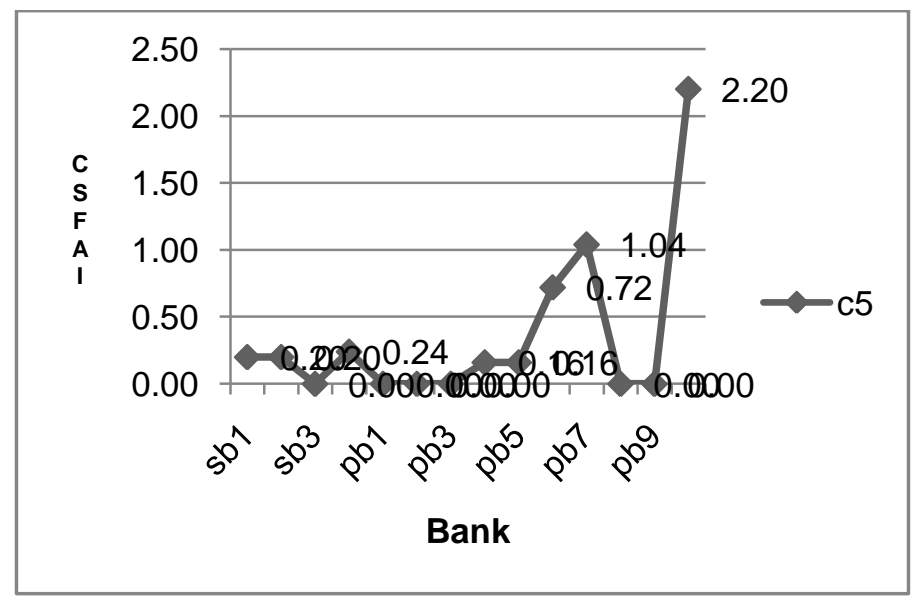

FIGURE 5: Distribution of category specific foss adoption index for c5.

As in Fig. 5, the values obtained by the banks for Back Office category, also seem to be quite poor for many banks. There are so many cases where the score is 0 . With enough FOSS applications in this respect this is an important matter to be taken into consideration.

The distribution of the particular index for $\mathrm{c} 7$ is shown on Fig. 6 . 
Vol. 1, No. 1 (2013) 20-34

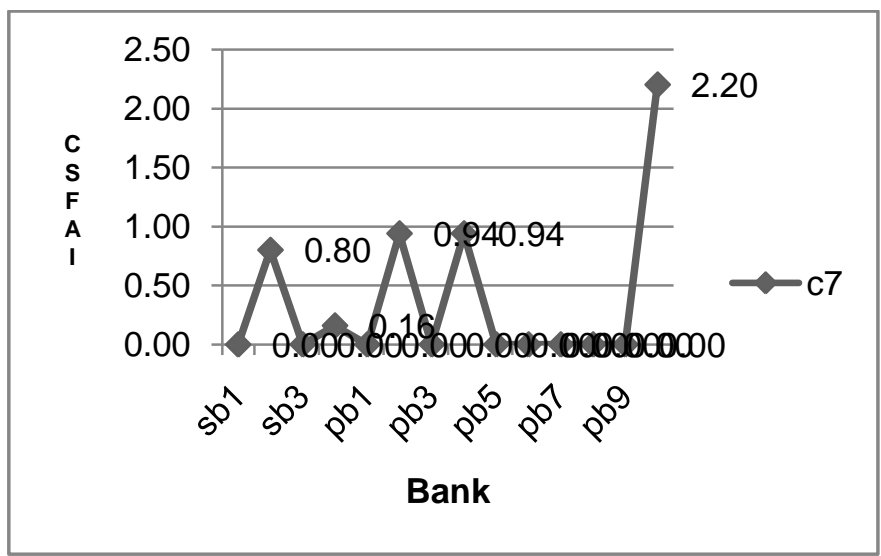

FIGURE 6: Distribution of category specific foss adoption index for $\mathrm{c} 7$.

It is clear that the scores in this category are very low, as well, except one case which is 2.2 . There are several 0 scores too.

Figure 7 illustrates the distribution of the index with respect to c8, Programming Languages and Tools.

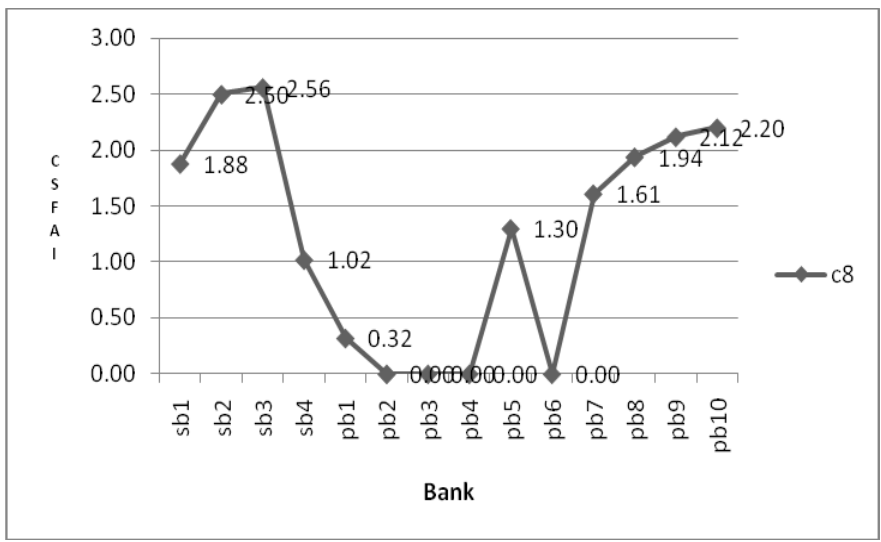

FIGURE 7: Distribution of category specific foss adoption index for c8.

Though there are few a 0's, there can be some adoption with respect to this category. This is not very surprising considering the fact that, there are so many FOSS tools such as Network Monitoring Tools and Programming Languages, which are being widely used in the industry.

In summary above facts reveals the following facts.

I. The average FOSS adoption indexes with respect to different categories are not so high.

II. The index values for $\mathrm{c} 1, \mathrm{c} 3, \mathrm{c} 4$ and $\mathrm{c} 6$ are zero for all the banks.

III. The scores are high in cases of $\mathrm{c} 2$ and $\mathrm{c} 8$ in general.

\section{CONCLUSIONS AND RECOMMENDATIONS}

This research aimed at a very specialized business segment, where standards related to quality of information, security and reliability play a key role. Another aspect discovered during the research was the highly regularized and standardized nature of this business, which leaves very little room for innovation. The products (types of services such as different types of loans, savings packages, and pawning etc) available in all the banks are more or less the same, and the procedures too have very slight 
variations. In addition, the Central Bank of Sri Lanka imposes strict regulations on the industry, and banks have to meticulously comply with them. Due to these reasons, IT managers have a very limited freedom to do R\& D type activities in their job. Even if they do so; it is related to less important activities which do not fall into the main stream banking operations.

On the other hand, due to the highly standardized nature of the industry, there are well tested commercial software applications, which have a very good reputation among banking community, for critical applications such as core banking and payment gateways. For example, the author identified that, many banks preferred AS400 based solutions provided by IBM, due to the simple reason that IBM is a business giant in the world and the products supplied by them are well tested and accepted by most of the bankers in the world. This is true for the payment gateways such as Cirus, Master Card which is an area dominated by a few companies. In this context even though the cost associated with it may be very high, the banks prefer to select such products due to the very high reputation.

It is therefore not surprising to find that, Core Banking and Intra-Banking categories do not have a single FOSS product in any bank. It is worth considering that Front Office and Value Adding categories too have zero adoption among banks.

In respect of the Front Office category, one reason, why banks are reluctant to select FOSS applications is the higher number of installations associated with this category and the a very high demand for reliability as well. For example, if Ubuntu is used at front desks of bank branches, there may be several thousand installations for an average bank and the need for a lot of effort support, in the absence of a large number of trained persons for such applications. The commercial products such as Microsoft provide onsite support and sometimes have even regional branches for supporting. In contrast, there is lesser support with the device drivers and so on for FOSS applications, with regard to very special hardware items such as pass book printers, scanners and so on, which are commonly being used for front office operations. Another reason is the user's resistance for FOSS applications as front office machines. Employees who work on front office functions are average banking officers who do not have any exposure to FOSS applications. Many are familiar with very common applications such as Windows, since they use them more often. In case of ATM machines, no hardware vendor support is found for FOSS products.

Lack of FOSS adoption in Value Adding category and very low scores in Back Office as well as Office Applications categories is another important finding. In cases of Value Adding category, there are good FOSS applications associated. It is worthwhile to note that banks have not look into such options. On the other hand, banks seem to use a very limited number of Back Office applications and Office Applications, though there are good FOSS options. One reason related to Office Applications is the poor user interfaces of FOSS Office Applications, such as Open Office. Again there is a considerable resistance for FOSS Office Applications, because they are familiar with Microsoft products which are being commonly being used in their homes and so on. On the other hand, there are some quality issues with respect to FOSS based office applications such as Open Office. Some examples are problems of running macros written under Windows product, poor formatting facilities.

It is also interesting to note that the Infrastructure category has a good adoption among many banks. This is quite important considering the fact that it is a highly critical area in a bank. Well known products in this category, namely Linux and Apache has contributed a lot for this score. Another important candidate in this category is Squid which has good adoption. Availability of expertise in these applications, centralized nature of usage, and usage only by IT expertise (not average users) and also the good image for such products all over the world may be some of the reasons behind this finding. Due to similar reasons, vendors of other proprietary software and hardware also have a very good support on these applications. For example Oracle, which is a very popular database engine in the industry, supports several versions of Linux.

There is a high level of adoption in case of Programming Languages and Tools category as well. This category has a lot of FOSS options, such as popular browser Firefox, scripting language PHP and so many small software components which are very useful for minor activities. 
Accountability is one area which is highly demanded by the banking sector. This is natural due to the nature of the business banks are involved in, as explained earlier in this section. Lack of adequate commercial support for FOSS applications in Sri Lanka can be considered as one main reason for the poor adoption of FOSS for critical functions.

In general banks do not get best usage of the features unique for FOSS. This is an indication of the lack of technical expertise, which is essential for innovations. Usually the IT departments in banks are dominated by senior bankers who have switched to IT in later stages of their career. Due to the same reasons, many FOSS trained personnel are not available in banks. In the absence of strong policy initiatives to support FOSS in Sri Lanka, the role of boundary spanners in second level command of the IT departments, seem to be one of the main sources which can build up a case for higher adoption of FOSS, as against the initiatives taken by top managers.

Many banks do not seem to use FOSS with strong strategic reasoning. One reason behind this would be the lack of technical expertise in the banks of Sri Lanka. The other reason is the lack of commercial FOSS environment in Sri Lanka to provide good support for such applications. The author did not find any bank which Sri Lanka who adopts firmware for Service Oriented Approach (SOA) which offers to Banks a lot of long term strategic benefits such as integration.

The research revealed that the FOSS adoption in respect of high level FOSS applications which are critical for main business of the bank can be increased by augmenting of the General FOSS Adoption Index. Strategic usage of FOSS and increasing FOSS awareness are two areas that should be given more attention as per the model presented. The Sri Lankan government seems to have a major role to play in this area since those are related to policy matters.

In summary, FOSS should be considered not as a different family of software products, which is usually free, but as a strong business model, which has been very effective, even among software giants such as IBM, Google and FaceBook. However, the propensity for the adoption of FOSS products in Sri Lankan banks seems to be very poor. Though some banks have better ratings, they too do not get the use of features unique to FOSS. This is simply the result of a few second level managers, operating as boundary spanners, thereby resulting in the long term strategic benefits of same being very low. For example, once they leave the bank, a new officer will not continue with those applications. There are very good benefits that FOSS can offer to banks, though one cannot expect to operate on FOSS applications alone. It is more important to increase the FOSS adoption in the areas such as Infrastructure, Back Office which have higher criticality and this can be done by the incorporation of FOSS in IT strategic planning and the increase of FOSS awareness.

\section{REFERENCES}

[1] R. Glosh and R. Glott, "Results and policy paper from survey of Government authorities. Maastrict, The Netherlands: MERI, University of Maastrict.," Free/Libre and Open Source Software: Policy Support, 25-Aug-2005. [Online]. Available: http://flosspols.org/deliverables/D03HTML/FLOSSPOLSD03\%20local\%20governments\%20survey\%20reportFINAL.html. [Accessed: 07-Jan-2013].

[2] S. Walli, D. Gynn, and B. von Rotz, "The growth of Open Source Software in Organizations.," 2004. [Online]. Available:

http://books.google.com/books?hl=en\&lr=\&id=ELieXMxR1h4C\&oi=fnd\&pg=PR7\&dq=open+source\%2 Bbusiness\&ots=0otIXAKFLG\&sig=-

YoLB9aij8xShLK5SY11HBwCGcM\#v=onepage \&q=open\%20source\%2Bbusiness \&f=false. [Accessed: 07-Jan-2013]. 
[3] S. Saini, C. N. Krishnan, and L. N. Rajaram, "Open Source Adoption Index: Quantifying FOSS Adoption by an Organisation," Int. J. Ofopen Source Softw. Process., vol. 2, no. 3, pp. 48-60, Sep. 2010.

[4] A. Hars, "CiteSeerX - Working for Free? Motivations for Participating in Open-Source Projects." [Online]. Available: http://citeseer.ist.psu.edu/viewdoc/summary?doi=10.1.1.105.8675. [Accessed: 24-Aug-2011].

[5] Jon Brodkin, “We love open source'," Network World, 23-2010. [Online]. Available: http://www.networkworld.com/news/2010/082310-microsoft-open-source.html. [Accessed: 24-Aug2011].

[6] S. Shankland, M. Kane, R. Lemos, and C. Staff, "How Linux saved Amazon millions," update, vol. 5, p. 20, 2001.

[7] G. Dias and C. Weerasooriya, "An investigation into perception of Free and Open Source Software (FOSS) products among the Sri Lankan Organisations." University Of Moratuwa, Computer Science and Engineering Faculty, 2004.

[8] F. Davis, "Perceived usefulness, perceived ease of use, and user acceptance of information technology," Mis Quaterly, vol. 13, no. 3, pp. 319-339, 1989.

[9] P. Stacie, W. DeLone, and E. McLean, "Measuring Information Systems Success $\square$ : models, dimensions, measures and interrelationships," Eur. J. Inf. Syst., vol. 12, no. 3, pp. 12-55, 2008.

[10] B. Rossi, B. Russo, and G. Succi, "A study on the introduction of Open Source Software in the Public Administration," Open Source Syst., pp. 165-171, 2006.

[11] D. Noonan, P. Baker, and N. Moon, "OPEN SOURCE SOFTWARE POTENTIAL INDEX (OSPI): DEVELOPMENT CONSIDERATIONS," Context, 2008. 